\title{
Towards Understanding the Processes Affecting the CR Chondrite Parent Body: Coordinated Electron Microscopy Study of the Matrices of Antarctic CR Chondrites.
}

\author{
Neyda M. Abreu ${ }^{1}$ \\ ${ }^{1}$ Earth Science Program, Pennsylvania State University - DuBois Campus, DuBois, Pennsylvania, USA.
}

Introduction: Carbonaceous chondrites are samples of primitive asteroids that formed 4.56 billion years ago, and as such, preserve as record of the earliest geological processes occurring in the solar system. The members of the CR group that were minimally affected by asteroidal processes have received attention because they contain a variety of isotopically exotic organics and a higher abundance of minerals formed by stellar and interstellar processes [1]. However, members of the CR group have been affected by broad range of asteroidal alteration features [2]. The least altered CR chondrites are assigned to petrologic type 3 (CR3), whereas the CRs that record most extensive signs of aqueous alteration belong to petrologic type 1 (CR1). $\mathrm{CR}$ chondrites are dominated by two types of materials, FeNi metal-bearing igneous spherules called chondrules and micron-to-sub-micron silicate rich matrix. CR matrices hosts the organic and presolar materials and, along with FeNi metal, they are highly susceptible to asteroidal alteration. To understand the changes resulting from asteroidal processing, the largest TEM study of CR matrices was undertaken. Twenty-three FIB matrix sections from ten Antarctic CRs (EET 96259, GRA 95229, GRA 06100, GRO 95577, GRO 03116, LAP 02432, LAP 04516, LAP 04720, MIL 07525, MIL 090001) were analyzed by TEM. The samples were extracted from representative regions of matrix, selected using SEM BSE imaging.

Results and Discussion: The mineral assemblages observed in Antarctic CR matrices are given in Table 1. Unlike matrices of other chondrites the selected CR matrices are dominated by amorphous ferromagnesiosilica, which are abundant even in the most aqueously altered CR1, GRO 95577 where phyllosilicates were expected to be the most abundant phases. Given the degree of aqueous alteration previously observed in the chondrules of GRO 95577 [3], ferromagnesiosilica may contain structural $\mathrm{H} 2 \mathrm{O}$ and be resistant to crystallization into phyllosilicates. Although ferromagnesiosilica, phyllosilicates (Fig. 1), and FeNi sulfides occur in all meteorites, mineralogical trends established in the CR parent body are evident. Matrix mineralogy is simplest in the least altered CR2s (e.g. GRA 95229, LAP 02432), containing mainly amorphous ferromagnesiosilica, phyllosilicates, FeNi sulfides, and C nanoglobules. This is consistent with observations of CR3 matrices [4]. Secondary mineralogy in all meteorites is controlled by redistribution of Fe. BSE images show that Fe was removed from mm-sized FeNi grains that are found on the periphery of chondrules or embedded in matrix. Assemblages are most complex and variable in GRA 06100, GRO 03116, and EET 96259. Millimeter-sized FeNi grains are also most altered in these three meteorites - GRA 06100 shows the most extensive replacement textures [5]. Nanophase minerals stable under extreme low/high $\mathrm{fO}_{2}$ coexist in GRA 06100, GRO 03116, and EET 96259 (e.g., FeNi metal, FexSiy, wustite, enstatite, forsterite, fayalite, magnetite, and hisingerite). These meteorites show $\mu \mathrm{m}$-scale shock features, suggesting that their disequilibrium matrix assemblages formed as a consequence of impact processes. Multiple aqueous alteration styles are evidenced by the secondary assemblages in LAP 04516 and MIL 07525, which are distinct from those in GRO 95577. They contain nanophase toichillinite, which is common in CM2s, but not in previously studied CRs. In contrast, GRO 95577 contains $\mu \mathrm{m}$-sized magnetite and nanophase FeNi sulfides.

References:

[1] C. Floss et al. Astrophysical Journal 697 (2009), pp. 1242-1255. 
[2] N. Abreu PhD Dissertation. (2007)

[3] M. Weisberg and H. Huber Meteoritics \& Planetary Sciences 42 (2007), pp. 1495-1503.

[4] N. Abreu and A. Brearley. Geochimica et Cosmochimica Acta 74 (2010) pp. 1146-1171.

[5] N. Abreu and E. Bullock. Meteoritics \& Planetary Sciences 48 (2013) pp. 2406-2429.

[6] NMA acknowledges funds from NASA Cosmochemistry NNX11AH10G. Observations conducted at MRI-Penn State. Samples provided by Johnson Space Center Antarctic Meteorite Collection

Figure 1. TEM-EDS analyses of amorphous ferromagnesiosilica in CR matrices.

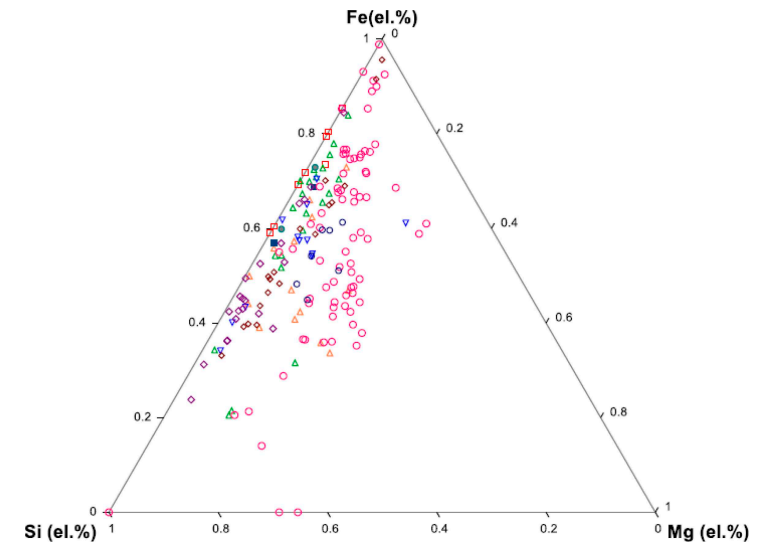

Table 1. Mineral assemblages in CR chondrite matrices.

\begin{tabular}{|c|c|c|}
\hline Meteorite & Common Matrix Minerals & Rare Matrix Minerals \\
\hline EET 96259 & $\begin{array}{l}\text { Ferromagnesiosilica, Ferrolizardite, Fe-sulfide, Fe-oxide } \\
\text { (prob. } \\
\text { Wustite) }\end{array}$ & \\
\hline GRA 95229 & Ferromagnesiosilica, Ferrolizardite, FeNi-sulfide & $\begin{array}{l}\text { Forsteritic Olivine, Enstatite, } \\
\text { Fe-oxide } \\
\text { (prob. Magnetite), } \\
\text { C-nanoglobules }\end{array}$ \\
\hline GRA 06100 & $\begin{array}{l}\text { Ferromagnesiosilica, Fe-rich Serpentine, FeNi-sulfide, } \\
\text { FeNi metal, } \\
\text { FexSiy, Fe-oxide (prob. Wustite and Magnetite), } \\
\text { Hisingerite }\end{array}$ & $\begin{array}{l}\text { Forsterite, Fayalite, Enstatite, } \\
\text { Garnet }\end{array}$ \\
\hline GRO 95577 & Ferromagnesiosilica, Fe-rich Serpentine, FeNi-sulfide & \\
\hline GRO 03116 & $\begin{array}{l}\text { Ferromagnesiosilica, Fe-rich Serpentine, FeNi-sulfide, } \\
\text { FeNi metal }\end{array}$ & Forsterite, Ferrosilite \\
\hline LAP 02432 & Ferromagnesiosilica, Fe-rich Serpentine, FeNi-sulfide & $\begin{array}{l}\text { Fe-oxide (prob. Wustite and } \\
\text { Magnetite), }\end{array}$ \\
\hline LAP 04516 & $\begin{array}{l}\text { Ferromagnesiosilica, Fe-rich Serpentine, Tochilinite, } \\
\text { FeNi-sulfide }\end{array}$ & Diopside, Pigeonite \\
\hline LAP 04720 & Ferromagnesiosilica, Fe-rich Serpentine, FeNi-sulfide & $\begin{array}{l}\text { FexSiy, Forsterite, Fayalite, } \\
\text { Enstatite, } \\
\text { Ferrosilite }\end{array}$ \\
\hline $\begin{array}{l}\text { MIL } 07525 \\
\text { MIL } 090001\end{array}$ & Ferromagnesiosilica, Fe-rich Serpentine, FeNi-sulfide & Tochilinite \\
\hline
\end{tabular}

